\title{
Autorização: Um Instrumento Inadequado para o Setor Elétrico
}

Elena Landau'

\section{Introdução}

O governo brasileiro iniciou, em meados dos anos 90, a reformulação do setor elétrico com o objetivo de prepará-lo para o processo de desestatização. ${ }^{2}$ Seguindo uma tendência internacional, essa reformulação baseou-se em três vertentes: (i) desestatização, (ii) desverticalização das atividades e (iii) marco regulatório calcado no princípio da eficiência.

A desverticalização do setor implicou a separação das suas quatro atividades: geração, transmissão, distribuição e comercialização. Os objetivos principais dessa reforma eram dar maior transparência aos custos efetivos de cada atividade e implementar a competição sempre que possível. Do ponto de vista da delegação ao particular, essas quatro atividades não mereceram o mesmo tratamento. Distribuição e transmissão, monopólios naturais em que inexiste a possibilidade de competição, ${ }^{3}$ permaneceram reguladas por contratos de concessão mesmo após

\footnotetext{
1 Economista, advogada e mestre em Economia pela PUC/RJ. Sócia do Escritório de Advocacia Sergio Bermudes. A autora agradece os comentários de Persio Arida, Sergio Bermudes, Carolina Fidalgo, Fabiano Robalinho, Patrícia Sampaio e Augusto Werneck, este último orientador da monografia de graduaçāo na qual este artigo está baseado.

2 Para uma análise das razōes que levaram ao processo de desestatização e reformulaçāo do modelo do setor elétrico, veja-se LANDAU, Elena; SAMPAIO, Patrícia. Conseguirão as PPP's atrair os investimentos pretendidos? Revista de Direito da Associação dos Procuradores do Rio de Janeiro, Rio de Janeiro: Lumen Juris, 2006, v. XVII, p. 137-160, e Id. Setor elétrico: uma visão introdutória. In: LANDAU, Elena (Org.). Regulação jurídica do setor elétrico, Rio de Janeiro: Lumen Juris, 2006.

3 Nos monopólios naturais, os custos fixos sāo muito elevados relativamente à demanda, de forma que, se puderem ser diluídos por toda a produção do mercado, uma única firma fornecendo aquele produto pode ter um custo médio de produção menor do que duas firmas igualmente eficientes, cada
} 
a privatização. Por sua vez, geração e comercialização poderiam ser consideradas atividades econômicas em sentido estrito, passíveis, portanto, de exploração também fora do sistema de concessāo, próprio dos serviços públicos. Essas atividades poderiam também ser exploradas sob a forma de autorização, o que explica por que a maioria das usinas térmicas foram autorizadas.

Uma discussão entāo se iniciou em torno da legalidade da utilização da autorização. A Constituição Federal prevê, nos artigos 21 e 175, como formas de delegação dos serviços públicos ou de atividades de interesse público, a autorização, a concessão e a permissão. Interessam a este trabalho especialmente as duas primeiras, já que a permissão não é instituto normalmente utilizado no setor de energia. A autorização é discricionária e não prevê indenizaçāo no caso de sua revogação. Já a concessão é regulada por contrato, prevendo indenização e as condições de sua extinção. A autorização tem como uma de suas vantagens a sua flexibilidade e conceitualmente é adequada para os casos de investimentos de pequeno montante. A concessão, ao prover melhores garantias para o investimento privado, ao mesmo tempo em que caracteriza com mais precisão as obrigaçōes do concessionário, é adequada para os casos em que os investimentos são de grande monta e o serviço por razões técnicas ou regulatórias é prestado em situações onde a competição é limitada. Torna-se, então, imperativo regular o poder do concessionário sobre o preço ou a qualidade dos seus serviços, o que em grande parte é feito através do contrato de concessão que define seus direitos e deveres.

Uma parte da doutrina, ao considerar que a energia elétrica em qualquer segmento é serviço público, alegava a impossibilidade da sua exploração em regime privado. Em consequiência, qualquer atividade do setor, mesmo em áreas competitivas, deveria ser explorada pelo particular através do que determina o art. 175, isto é, sua delegaçāo só poderia se dar por permissāo ou concessão. ${ }^{4}$

Como a concessão parece ser uma forma de delegação menos ágil do que a autorização, o poder público, ao defrontar-se com as complexidades de um contrato de concessão, e premido pela urgência na provisão de serviços, optou inúmeras vezes pela autorizaçāo como forma de funcionamento de atividades do setor elétrico, especialmente para a implementação de usinas termelétricas. Criou-se assim uma situação em que os direitos do investimento privado ficaram mal definidos ao mesmo tempo em que o poder público é obrigado a introduzir retroativamente e caso a caso as regulamentações sobre a natureza dos serviços a serem prestados.

O fato é que, independentemente do debate da inconstitucionalidade das autorizações, tais empreendimentos, pelo fato de demandarem aporte de recursos de grande monta, deveriam ter sido delegados sob a égide da concessão já que

uma das quais tendo de incorrer nos mesmos custos fixos, mas tendo de diluí-los por apenas metade da produçāo total. POSNER, Richard. Economic analysis of law. Boston: Little, Brown and Company, 1988, p. 343 e CASTELAR, Armando Pinheiro e SADDI, Jairo. Direito, economia e mercados, Editora Campus, 2006. p. 266-275.

4 BANDEIRA DE MELLO, Celso Antonio, Curso de direito administrativo. 15. ed. São Paulo: Malheiros, 2003. 
não está presente o elemento de precariedade. De fato, para suprir as deficiências da autorização como titulação para estas atividades, os atos autorizativos do regulador trazem prazos para a sua exploração e até mesmo a reversão de bens para a União, institutos típicos da concessão. Ou seja, em tais casos, ainda que a titulação tenha sido feita via autorização, estes empreendimentos se submeteriam ao regime jurídico próprio da concessão e assim, ainda que formalmente denominadas de autorização, materialmente deveriam ser consideradas concessões, ${ }^{5}$ no que diz respeito aos deveres do titular.

Este artigo pretende estimular o debate doutrinário sobre o tema e, ao mesmo tempo, procura discutir as razões que levaram à ampla utilização do instituto da autorização para delegação de potenciais de geração de energia elétrica aos particulares no contexto da reestruturação do setor elétrico ocorrida em meados dos anos 90.

\section{Formas de delegação dos serviços públicos: arts. 175 e 21 da Constituição Federal}

\section{I As formas de delegação: concessão, permissão e autorização}

As formas de delegação ao particular da exploração de serviços de energia estão previstas na Constituição em dois artigos: art. 21, XII, b e art. 175. Para o setor elétrico o texto constitucional prevê que:

Art. 21: Compete à União:

XII - explorar, diretamente ou mediante autorização, concessão ou permissão:

b) os serviços e instalaçōes de energia elétrica e o aproveitamento energético dos cursos de água, em articulação com os Estados onde se situam os potenciais hidroenergéticos;

Já o art. 175 admite a delegaçāo de serviços públicos, onde a energia tradicionalmente se insere, apenas nas formas de concessão e permissão. A Lei nº 8.987/95 regulamentou esse comando constitucional e nos seus artigos iniciais define os dois instrumentos de delegação, a saber: concessão de serviço público, concessão de serviço público precedida de execução de obra pública e permissão de serviço público, sendo a concessão formalizada por contrato, e a permissão, delegada a título precário. A autorização, por sua vez, está prevista na Lei $n^{9}$ 9.074/95.

A concessão é a mais tradicional forma de delegação utilizada pelo Poder Público para transferir a terceiros a execução de serviços públicos e seu caráter contratual é indisputável.

\footnotetext{
5 Ver a respeito JUSTEN FILHO, Marçal. Teoria geral das concessóes de serviço público. São Paulo: Dialética, 2003.
} 
Após processo de segmentação das atividades do setor elétrico, vários empreendimentos nas áreas da distribuição e da transmissão de energia elétrica foram concedidos ao particular, sempre através de licitação, tendo como base o contrato de concessão.

O contrato de concessão era, e ainda é, o instrumento de regulaçāo básico e fundamental para a atividade de distribuição e transmissão de energia. ${ }^{6} \mathrm{~A}$ definição de direitos e deveres das partes no contrato, além de seguir a determinação legal prevista na Lei de Concessōes, procura conciliar os objetivos antagônicos ${ }^{7}$ representados pelo interesse público e a exploração empresarial da atividade, a serem mediados pelo órgão regulador. ${ }^{8}$ A lei define que as partes do contrato sāo, de um lado, o Poder Concedente e, de outro, o concessionário, pessoa jurídica ou consórcio de empresas, que deve demonstrar capacidade para o desempenho por sua conta e risco e por prazo determinado.

A permissāo é instrumento algo diverso da concessão. A Lei n ${ }^{9} 8.987 / 95$ em seu art. $2^{\circ}$, IV, define permissão como delegação a título precário, mediante processo licitatório.

As características da permissão são: precariedade, revogabilidade unilateral e contrato de adesão. A permissão é definida por Maria Sylvia Di Pietro como "ato administrativo unilateral, discricionário e precário, gratuito ou oneroso, pelo qual a Administração Pública faculta ao particular a execução de serviço público ou a utilização privativa de bem público por terceiros". ${ }^{9}$

Ou seja, a revogação não daria direitos aos permissionários contra a Administração, admitindo-se, é evidente, que ela tenha sido realizada através de ato motivado. Nas palavras de Marçal Justen Filho: ${ }^{10}$

\footnotetext{
6 Também na geração é comum a delegação através de contratos de concessão, como ocorreu na privatização das geradoras da antiga CESP e da Eletrosul. No entanto, nos interessa aqui neste trabalho focar nos segmentos de geração que foram explorados pelo particular com base em autorizações.

"Não seria exagero afirmar que a concessāo de serviço público é uma tentativa de composição entre alternativas radicalmente diversas. Trata-se de uma espécie de meio termo entre concepçōes opostas e contraditórias [...] A concessão se vincula, primeiramente, à temática do serviço público. Isso significa o compromisso do atendimento a necessidades essenciais, diretamente relacionadas com o princípio da dignidade da pessoa humana, o que conduz usualmente à participação estatal. [...] Mas a concessão também se relaciona à exploraçāo empresarial das atividades de serviço público, desenvolvida pela iniciativa privada sob a concepção da lucratividade. Daí se segue a aplicação de princípios peculiares ao âmbito não estatal, tais como a tutela à propriedade privada, à livre iniciativa e (eventualmente) à livre concorrência" (JUSTEN FILHO, op. cit. p. 11).
}

8 Esta tensāo entre os interesses das partes tem sido expressa na experiência brasileira na dificuldade de concretizaçāo dos princípios da modicidade tarifária e do equilíbrio econômico financeiro. Mesmo quando se ultrapassa essa questão junto ao órgão regulador, suas decisōes têm sido levadas ao Judiciário, que em primeira instância tem revisto as decisōes da ANEEL, gerando situaçōes onde o equilíbrio econômico-financeiro do contrato não é observado. LANDAU, Elena e VELLOSO, Antonio Carlos, Tarifas de energia e respeito aos contratos, Valor Econômico, em 23/10/2006.

9 DI PIETRO, Maria Sylvia Zanella. Parcerias na administração pública: concessāo, permissāo, franquia, terceirização e outras formas. 5. ed. São Paulo: Atlas, 2006, p. 147-148.

10 JUSTEN FILHO, Marçal, op. cit., p. 112. 
"A extinção a qualquer tempo sempre é possivel, mesmo para uma concessão. A questão fundamental é outra e consiste na indenização devida ao particular. $\mathrm{Na}$ hipótese da extinção antecipada da concessão por conveniência da administração (encampação) é assegurada indenização ao particular [...]. Já no caso da permissão, a extinção a qualquer tempo não produz direito à indenizaçāo."

Nesta linha, Celso Antonio Bandeira de Mello aponta que a diferença entre permissão e concessāo residiria no fato de a primeira ser utilizada quando o Estado não desejasse constituir o particular em direito contra ele, mas apenas em face de terceiros.

Maria Sylvia Di Pietro considera a precariedade o fator de distinção entre os dois institutos e afirma que "a fixação de prazo na permissão faz desaparecer a diferença entre esse instituto e a concessão, já que ocorrerá a perda da precariedade e o permissionário se tornará titular de direito subjetivo oponível à Administração"." Note-se neste aspecto que a lei de concessão não permite a outorga sem prazo determinado, que funciona como uma garantia para o concessionário, na medida em que o prazo é fator determinante para a equaçāo financeira do projeto que originou a proposta vencedora em processo de licitação. Por este motivo, a interrupção do contrato antes de seu término deve obedecer ao que prevê o art. 35 , incisos II a VI, da Lei nº 8.987/95, que tratam da extinção da concessão, antes do advento do termo contratual.

A principal diferença entre os institutos da concessão e permissão residiria, portanto, na própria destinação de cada um deles, pois para obrigaçōes executáveis no longo prazo e que demandem comprometimento patrimonial do concessionário não teria sentido o instituto da permissão, que se destina a situações precárias.

A autorização é a terceira forma de outorga aplicável ao setor elétrico. Ela não está prevista no art. 175, mas sim no art. 21 , XII, $b$, da Constituição Federal. A autorização no direito brasileiro tem três acepçōes: (i) aquela praticada no exercício do poder de polícia, sem a qual o desempenho da atividade seria legalmente proibida; (ii) a de uso, com a qual a Administraçāo faculta ao particular o uso de bem público, e, por fim, que nos interessa em particular, (iii) a de serviço público. E, em qualquer caso, a autorização é ato unilateral, discricionário e a título precário. Nas palavras de Fabio Konder Comparato:

"A autorização distingue-se da concessão porque é um ato unilateral e não um contrato, e também porque o autorizado não desempenha propriamente serviço público, mas uma atividade considerada de interesse coletivo. Aproxima-se das permissōes na medida em que, como estas, é um ato discricionário". ${ }^{12}$ 
De acordo com o parágrafo único do art. 170 da Constituição Federal algumas atividades previstas em lei só poderão ser exercidas pelo particular com a autorização prévia da Administração. A exigência do ato autorizativo na partida diferencia essas atividades daquelas privadas em sentido estrito para as quais prevalece $o$ princípio da livre iniciativa.

A necessidade de autorização prévia também significa que tais atividades podem estar sujeitas a algum grau de regulação durante seu exercício. ${ }^{13} \mathrm{Em}$ geral, as autorizações são dadas por órgãos específicos do setor a que estas atividades se vinculam, que no caso da energia elétrica é a ANEEL.

É evidente que a autorização só será concedida para empresas que comprovem sua capacidade para cumprir com as exigências do serviço a ser prestado, cujo objeto será definido no próprio ato de autorização. Ainda que haja um conjunto de critérios gerais ou exigências mínimas definidas em lei a autorização será examinada discricionariamente pela Administração. ${ }^{14} \mathrm{~A}$ discricionariedade também estará presente na revogação do ato, que, dada sua precariedade, pode ocorrer a qualquer tempo, sem necessidade de indenização ao particular. Este é um aspecto muito relevante no caso de exploração de serviços públicos por particulares mediante autorização, em especial, quando são realizados grandes investimentos, pois a fragilidade do vínculo é um fator que pode afastar os investidores. Para estas situações, Sara Jane Leite, a partir da Lei Geral de Telecomunicações, estabelece uma diferença entre autorizaçōes clássicas, discricionárias e as autorizações vinculadas, estáveis:

"Entretanto, o que restará evidente é que não se está exclusivamente no terreno das autorizações clássicas, tidas como atos discricionários; pois, referido instituto passou a ser adotado como um instrumento viabilizador da competição, sob a denominação de 'autorização vinculada' Torna-se mister esclarecer que não se trata de nova 'modalidade' de autorização ou ato autorizatário, mas de uma evolução do provimento decorrente do novo cenário propiciado pelo processo de desestatização, caracterizado pela prestação de alguns serviços públicos num regime de direito privado, o qual sobrevive ao lado do regime de direito público, por meio de concessão e permissão. Significa que a referida autorização, por opção legal, pode

\footnotetext{
13 ARAGĀO, Alexandre. Atividades privadas regulamentadas. Revista Forense, v. 383, 2006.

14 "Seja como for, a autorização administrativa implica sempre um exame caso a caso, sem que haja fixação prévia de regras gerais, proibitivas ou permissivas. É neste sentido que se pode conceituá-lo como ato discricionário. Se a lei fixasse um elenco taxativo de requisitos, preenchidos os quais o particular teria o direito a obter o provimento administrativo, à Administração competiria tão-só verificar o implemento dessas exigências, sem nenhuma latitude de apreciaçāo ulterior [...]. Mas no caso das autorizações administrativas para o exercício de atividade, o que a lei dá, quando dá, à Administração, é apenas um critério geral ou uma diretriz do tipo 'interesse coletivo', 'respeito às condições de mercado' e outras quejandas" (COMPARATO, Fabio Konder, op. cit., p. 243).
} 
ser discricionária ou vinculada. Aquela, caracteriza-se pela precariedade, enquanto esta, pela estabilidade." 15

Para a autora, portanto, em algumas situações haveria uma limitação à precariedade do ato autorizativo, que dependeria das características das atividades para as quais ela estaria sendo outorgada. Para o setor elétrico, entretanto, ao contrário do que ocorre na telefonia, a lei nada diz sobre as características do ato autorizativo, definindo somente o seu objeto.

A distinção entre permissão e concessão, como visto, se daria quanto à sua destinação, precária num caso e não precária no outro. Já a diferença entre autorização e as outras duas formas de delegação não parece tão simples de ser estabelecida. Note-se que, diferentemente do art. 175, que exige licitação para a concessão ou para a permissão, para a autorização esta não é obrigatória. De fato, a produção independente de energia térmica dispensa a licitação, devendo o interessado comprovar sua capacidade em atender as exigências técnicas para o fornecimento de um serviço adequado para obter a autorização da ANEEL. As autorizações são concedidas a determinadas empresas ou consórcios, cujas características e capacidade foram devidamente apreciadas caso a caso pelo Poder Público, o que caracteriza a discricionariedade do ato autorizativo em oposição à delegação via concessão, que obrigatoriamente deve ser precedida de uma licitação, sem espaço maior para discricionariedade por parte da Administração. ${ }^{16}$

Como a permissão, a autorização é outorgada a título precário por ato unilateral da Administração. Mas ao contrário da primeira tem sido bastante utilizada como forma de delegação no setor elétrico. A Lei nº 9.074/95 prevê, em seus arts. $6^{\circ}$ e $7^{\circ}$, o objeto da autorização:

"Art. 60 As usinas termelétricas destinadas à produção independente poderão ser objeto de concessão mediante licitação ou autorização.

Art. $7^{\circ}$ São objeto de autorização:

I - a implantação de usinas termelétricas, de potência superior a 5.000 $\mathrm{kW}$, destinada a uso exclusivo do autoprodutor;

II - o aproveitamento de potenciais hidráulicos, de potência superior a $1.000 \mathrm{~kW}$ e igual ou inferior a $10.000 \mathrm{~kW}$, destinados a uso exclusivo do autoprodutor.

\footnotetext{
is FARIAS, Sara Jane Leite de. Regulação jurídica dos serviços autorizados. Rio de Janeiro: Lumen Juris, 2005, p. 86. O art. 131 da Lei n" 9.472/97 define a autorizaçāo como ato vinculado: "A exploraçāo de serviço no regime privado dependerá de prévia autorizaçāo da Agência, que acarretará direito de uso das radiofreqüências necessárias. $\$ 1^{\circ}$. Autorização de serviço de telecomunicações é o ato administrativo vinculado que faculta a exploração, no regime privado, de modalidade de serviço de telecomunicações, quando preenchidas as condições objetivas e subjetivas necessárias."

Apesar de não ser exigida a licitaçāo em inúmeros casos no setor elétrico, a ANEEL concedeu esta titulação após processo licitatório, aproximando uma vez mais as autorizaçōes do setor ao instituto da concessāo.
} 
Parágrafo único. As usinas termelétricas referidas neste e nos arts. $5^{\circ} \mathrm{e}$ $6^{\circ}$ não compreendem aquelas cuja fonte primária de energia é a nuclear."

E o Decreto n².003/96, que regulamenta o Produtor Independente de Energia Elétrica (PIE) e a autoproduçāo, estabelece que:

"Art. 1" A produção de energia elétrica, por produtor independente e por autoprodutor, depende de concessão ou autorização, que serão outorgadas na forma da legislação em vigor e deste Decreto.

Art. $4^{\circ}$ Dependem de autorização:

I - a implantação de usina termelétrica de potência superior a 5.000 $\mathrm{kW}$, destinada a autoprodutor e a produtor independente;

II - o aproveitamento de potencial hidráulico de potência superior a $1.000 \mathrm{~kW}$ e igual ou inferior a $10.000 \mathrm{~kW}$, por autoprodutor.

Observa-se, pelo objeto das autorizaçōes no setor elétrico, que este instrumento foi utilizado para a exploração de atividades de grande porte. Como vimos, a doutrina é clara quando afirma que não se deveria admitir a permissão para investimentos cuja amortização exija longo prazo exatamente em função de seu caráter precário. ${ }^{17}$ Analogamente, a autorização não deveria ter sido aplicada ao setor elétrico nos casos que envolvem elevado grau de comprometimento patrimonial do investidor. ${ }^{18}$

Além disso, menção deve ser feita às dificuldades para diferenciar entre concessão e autorização no setor elétrico, já que algumas obrigações típicas de concessionários são impostas às empresas autorizadas. Há quem as diferencie pelo regime jurídico a que se submetem, isto é, a concessão se aplicaria à exploração de serviços públicos, sujeita, portanto, necessariamente a um regime público, o que não se observaria na autorização, que pode estar, e para muitos sempre estará, subordinada a um regime de direito privado. Nesta linha, Maria Sylvia Di Pietro, tendo como base a legislação aplicável ao autoprodutor e produtor independente, afirma, que:

"a autorização é dada no interesse exclusivo do particular que a obtém. [...] Ele não exerce uma atividade que vá ser usufruída por terceiros, mas apenas por ele mesmo. Vale dizer que aquela mesma atividade que constitui serviço público propriamente dito, quando prestado diretamente pelo Poder Público ou pelas concessionárias ou permissionárias, praticamente perde essa qualidade quando prestado mediante autorização, por faltar-lhe

JUSTEN FILHO, Marçal, op. cit., p. 113, entre outros.

18 Ciente de que a revogação a qualquer tempo cria um nível de risco insuportável para o investidor privado, a legislação prevê o instituto da reversāo típico da concessão. Voltaremos a este ponto mais adiante. 
uma característica essencial que é o atendimento de necessidades coletivas" (grifo nosso). ${ }^{19}$

Dinorá Grotti busca dar uma rationale ao uso destes instrumentos de delegação argumentando que escolha de cada instituto decorreria da maior ou da menor presença ou controle do Estado na execução do serviço delegado, isto é, existiria uma gradação entre os três institutos:

"Na terceira acepção, que ora nos interessa - qual seja, de autorização de serviço público -, 'autorização é o ato administrativo, unilateral e discricionário pelo qual o Poder Público delega ao particular a exploração de serviço público, a título precário'. Criou-se uma gradação entre os institutos da autorização, permissão e concessão em funçāo do grau de participação ou de controle do Poder Público na execução do serviço delegado ao particular." 20

Sendo a autorização ato discricionário, as resoluções da ANEEL não obedecem a um critério uniforme, ao contrário do que se observa nos contratos de concessão que seguem as normas definidas na Lei $n^{0} 8.987 / 95$. Algumas autorizações foram concedidas após processo licitatório, outras têm prazo de exploração pré-estabelecido, outras ainda prevêem o instituto da reversão, partilhando assim em um grau ou outro várias das características típicas da concessão. Diante da diversidade destes atos e do fato de terem sido utilizados para autorizar a exploração de serviços públicos que não possuem caráter precário, torna-se complexa a tarefa de definir as características das autorizaçōes para o setor elétrico. Daí a prática de denominá-las como autorizaçōes sui generis, autorizaçōes especiais ou expressōes correlatas.

\subsection{A conciliação dos arts. 2I, XII, b, e 175 da Constituição Federal}

Pelo art. 21, a outorga pode ser feita de três formas, enquanto o art. 175 prevê apenas duas formas. Assim, se considerarmos que energia elétrica em toda sua cadeia é serviço público, haveria uma contradição no texto constitucional, pois não seria aplicável a sua delegação através da autorização, conforme prevista no art. 21, mas apenas nas formas de concessāo e permissão segundo o art. 175. Nesta linha destaca-se Celso Antonio Bandeira de Mello, ${ }^{21}$ que busca conciliar as duas

\footnotetext{
19 DI PIETRO, Maria Sylvia Z., op.cit, p. 152.

20 GROTTI, Dinorá Adelaide Musetti. Teoria dos serviços públicos e a sua transformação. In: SUNDFELD, Carlos Ari. Direito administrativo econômico. São Paulo: Malheiros, 2000, p. 66-67.

21 MELLO, Celso Antonio Bandeira de, op. cit., p. 629-630. Neste sentido, podemos citar também Maria Sylvia Zanella Di Pietro, autora que mesmo para as telecomunicações enxerga uma inconstitucionalidade: "E essa impropriedade da utilização do instituto da autorização decorre de outra impropriedade, para nāo falar em flagrante inconstitucionalidade: o que a lei (9427-97) fez foi privatizar (não a execução do serviço, como ocorre na autorização, permissão ou concessāo), mas a própria atividade ou, pelo menos, uma parte dela que não encontra fundamento na Constituição." Op. cit., p. 126-127.
} 
disposições, interpretando o sentido do uso da expressão autorização na Constituição Federal. Para ele, a autorização caberia em duas hipóteses apenas: (i) para os serviços de telecomunicações que não são propriamente serviço público, como o radioamador, como também prevê o art. 223, e (ii) nos casos em que se trata efetivamente de serviços públicos, mas aplicável apenas em situações emergenciais.

Note-se que o setor elétrico não recebe o mesmo tratamento normativo dado aos serviços de telecomunicações, isto é, o de destacar dentre os serviços de energia elétrica aqueles que não são "propriamente serviço público" e, portanto, passíveis de serem tratados como atividades privadas regulamentadas. ${ }^{22} \mathrm{O}$ corolário desta posição seria então considerar inconstitucionais as autorizações outorgadas nas atividades do setor elétrico. ${ }^{23}$

No entanto, essa aparente contradição da expressão autorização poderia ser resolvida através da análise das características dos segmentos que compõem a cadeia energética, circunscrevendo a autorização às atividades que não atingem a coletividade, a exemplo do que ocorre nas telecomunicações. Neste sentido, Maria João Pereira Rolim faz a seguinte ressalva: "O que não se admite é a utilização do instituto da autorização para serviços públicos nos quais se verifique a necessidade de oferta de utilidade ao mercado, conforme o princípio da universalidade", ${ }^{24}$ o que significaria, por exemplo, que onde não ocorresse a exigência da presença da prestação universal poderia haver a delegação via autorização. Para o setor de telecomunicaçōes, a própria lei estabelece as atividades onde a universalidade é dispensada, o que não ocorre no setor elétrico.

A rigor, poder-se-ia argumentar que haveria sempre algum grau de conteúdo público na prestação de serviços do setor elétrico, de forma que nenhum segmento da cadeia energética poderia ser considerado atividade econômica em sentido estrito. O produtor independente de energia, ainda que autorizatário, pode, por exemplo, comercializar energia também para concessionárias de serviço público, atingindo assim toda uma coletividade de consumidores cativos. Parte das divergências em relação ao regime jurídico aplicável a este setor vem do caráter de essencialidade da energia elétrica para a concretização dos princípios constitucionais como o da dignidade da pessoa humana e o da busca da redução das desigualdades sociais. A telefonia celular, por sua vez, não pode ser considerada um serviço essencial frente à opção, inclusive mais módica, da telefonia fixa.

\footnotetext{
22 Lei $n " 9.472 / 97$, art. 126. "A exploração de serviço de telecomunicações no regime privado será baseada nos princípios constitucionais da atividade econômica" (grifo nosso).

23 Carlos Ari Sundfeld comenta a propósito: "Alguns de meus colegas consideram que isso seria contrário à Constituição, pois dela decorreria o caráter necessariamente público da exploração, por particulares, das atividades reservadas ao Estado. Esse argumento baseia-se na crença de que existiria, implícito nas dobras constitucionais, um regime jurídico único para a exploração de serviços estatais (que mereceria o qualificativo de 'público')". Introduçāo às agências reguladoras, In: SUNDFELD, Carlos Ari. Direito administrativo econômico. Sāo Paulo: Malheiros, 2000. p. 33.
}

24 ROLIM, Maria Joāo Pereira, Direito econômico da energia elétrica. Rio de Janeiro: Forense, 2002, p. 153. 
O processo de desverticalização do setor elétrico revelou dois segmentos passíveis de serem classificados de atividade econômica no sentido estrito, que são a comercialização e a geração de energia. Nesses casos a autorização seria então um regime de outorga plenamente aplicável e legal. Os comentários de Marçal Justen Filho confirmam este entendimento:

"Somente se cogita de autorização para certas atividades econômicas em sentido restrito, cuja relevância subordina seu desempenho à fiscalização mais ampla e rigorosa do Estado. Havendo serviço público, não é o caso de outorga de autorização. Sendo outorga de autorização, não existirá serviço público. Logo e como o art. 21, incs. X a XII, da Constituição refere-se expressamente tanto à concessão como à autorização a propósito de certas atividades, tem de concluir-se que elas comportam exploração sob ambas as modalidades jurídicas." 25

Também é esta a interpretação de Dinorá M. Grotti, como se pode observar nos comentários abaixo:

"Existem três possibilidades para se considerar a referência constitucional ao regime da 'autorização' nos dispositivos acima citados: ou o art. 175 deixou de mencionar a 'autorização' entre as modalidades de delegação de serviços públicos, ao lado da permissão e concessão; ou introduziu-se erroneamente - por uma insuficiência técnica, no dizer de Celso Antônio Bandeira de Mello (Curso..., cit., p. 585, nota de rodapé 12) - o regime de autorização para um serviço público, conflitando com o art. 175; ou, finalmente, o regime de autorização estaria a demonstrar que alguns dos serviços elencados nos arts. 21 (incisos XI e XII) e 223 não são públicos, constituindo atividade econômica, enquanto os demais, sujeitos ao regime de concessão ou permissão, seriam serviços públicos". ${ }^{26}$

Assim, do mesmo modo que a Lei $n^{\circ} 9.472 / 97$ inovou na questão das autorizaçōes de serviço público de telecomunicaçōes ao contemplar a possibilidade de serviços reservados ao Estado serem submetidos ao regime de Direito Privado, ${ }^{27}$ a Lei n" 9.648/98 e o Decreto n" 2.655/98, que tratam da reestruturação do setor elétrico, deram caráter competitivo à comercialização e a alguns segmentos da geração. Esta legislação setorial vislumbra também a possibilidade destas atividades estarem submetidas ao regime de direito privado através de autorização prévia da administraçāo, ainda que para o setor elétrico a legislação nāo seja tão específica.

\footnotetext{
JUSTEN FILHO, Marçal, op. cit., p. 45.

GROTTI, Dinorá Adelaide Musetti, op. cit., p. 66.
}

Lei n" 9.472/97, art. 65: "Cada modalidade de serviço será destinada à prestação: I - exclusivamente no regime público; II - exclusivamente no regime privado; ou III - concomitantemente nos regimes público e privado. $\$ 1$ " Não serão deixadas à exploração apenas em regime privado as modalidades de serviço de interesse coletivo que, sendo essenciais, estejam sujeitas a deveres de universalização." 
Em última análise, a lacuna de certos textos legais não deve servir de pretexto para questionar o uso da autorização no setor elétrico. ${ }^{28}$

\subsection{A autorização no ordenamento jurídico da energia elétrica}

Nos diplomas legais que regulamentam a atividade do Novo Modelo do setor elétrico, ${ }^{29}$ a autorização está explicitamente prevista como uma alternativa à concessão como forma de exploração de empreendimentos pelo particular. Ela aparece na Lei $n^{\circ} 9.074$, de julho de 1995 , que veio complementar a Lei de Concessões, em seus arts. 6 e 7 que, como visto, definem o objeto das autorizações.

Este tipo de outorga foi, desde sua concepção, pensado para as formas de geração do produtor independente e do autoprodutor. O produtor independente é então definido na mesma lei, no art. 11 e no art. 12, e regulamentado no art. $2^{\circ}$ do Decreto $n^{\circ} 2.003$, de setembro de 1996 . Estāo aí estabelecidos os limites de sua atuação:

"Art. 12. A venda de energia elétrica por produtor independente poderá ser feita para:

I - concessionário de serviço público de energia elétrica;

II - consumidor de energia elétrica, nas condições estabelecidas nos arts. 15 e 16;

III - consumidores de energia elétrica integrantes de complexo industrial ou comercial, aos quais produtor independente também forneça vapor oriundo de processo de co-geração;

IV - conjunto de consumidores de energia elétrica, independentemente de tensão e carga, nas condições previamente ajustadas com o concessionário local de distribuição;

$\mathrm{V}$ - qualquer consumidor que demonstre ao poder concedente não ter o concessionário local lhe assegurado o fornecimento no prazo de até cento e oitenta dias contado da respectiva solicitação.

Parágrafo único. A comercialização na forma prevista nos incisos I, IV e $\mathrm{V}$ do caput deste artigo deverá ser exercida de acordo com critérios gerais fixados pelo Poder Concedente."

\footnotetext{
28 "A propósito, está em curso no Brasil um debate, um tanto surdo, quanto à possibilidade de a exploraçāo de serviço de titularidade estatal, como os de telecomunicaçōes e energia elétrica, ser feita em regime privado, o que foi previsto nas leis de reestruturação, como o intuito de introduzir a desregulação parcial desses setores (por meio de mecanismos como a liberalizaçāo do acesso dos exploradores ao mercado, a flexibilização dos preços, a ausência de garantia de rentabilidade etc.)" SUNDFELD, Carlos Ari, Introduçāo às agências reguladoras, In: SUNDFELD, Carlos Ari, op. cit., p. 33.

29 Novo Modelo refere-se àquele implementado no governo FHC e Novíssimo Modelo ao iniciado no governo Lula.
} 
O Decreto $n^{\circ} 2.003 / 96$ define, em seu art. $2^{\circ}$, Produtor Independente de Energia Elétrica como sendo a "pessoa jurídica ou empresas reunidas em consórcio que recebam concessão ou autorização para produzir energia elétrica destinada ao comércio de toda ou parte da energia produzida, por sua conta e risco"; e Autoprodutor de Energia Elétrica, como "a pessoa física ou jurídica ou empresas reunidas em consórcio que recebam concessão ou autorizaçāo para produzir energia elétrica destinada ao seu uso exclusivo". Em ambos os casos, trata-se da destinação de energia produzida por estes agentes, o que pressupõe investimentos na construção de plantas geradoras de energia.

No setor elétrico, o comprometimento patrimonial do empreendedor é grande em função das características tecnológicas da indústria. Provavelmente, levando em conta essa particularidade, este mesmo decreto prevê a possibilidade de encampação e de reversão, ao final do prazo da concessão ou autorização, de bens e instalações realizados para a geração independente e para autoprodução. Entretanto, só no caso de aproveitamento hidráulico haverá indenização de investimentos ainda não amortizados. Para as usinas termelétricas é dada a opção de remoção das instalações, sem direito à indenização. ${ }^{30}$

Tendo as autorizações, teoricamente, caráter precário, os atos autorizativos não deveriam trazer prazo definido para a exploração da atividade e nem gerar direitos do particular em relação ao Poder Público. Esta é a tese defendida por Maria Sylvia Di Pietro:

"Sendo a autorização, por definição, um ato precário, a rigor deve ser outorgada sem prazo, de tal forma que o Poder Público pode revogá-la, a qualquer momento sem direito à indenização; a fixação de prazo poderá investir o beneficiário de direito subjetivo oponível à Administração." 31

As resoluções da $\mathrm{ANEEL}^{32}$ mostram que, na prática, as autorizações no setor elétrico têm prazo determinado, e que, com exceção das usinas térmicas, está prevista a reversão à União das instalações. As autorizações para implantação de $\mathrm{PCH}$, por exemplo, têm previsão de reversão mediante pagamento de devida indenização, por serem hidrelétricas cujos bens se integram ao solo, no entanto, estes

\footnotetext{
30 A diferença de tratamento entre usinas hidrelétricas e termelétricas é natural em decorrência das características de cada uma delas, já que barragens integram-se naturalmente ao domínio público, e, de maneira geral, os bens utilizados na execução de serviços públicos concedidos são incorporados ao domínio público ao final do prazo do contrato. Esta destinação dos bens na maioria das vezes já vem integrada no cálculo da tarifa percebida pelo concessionário, o que garante direito à indenização apenas em casos de extinçāo da concessāo antes do advento do termo estabelecido no contrato.

3: DI PIETRO, Maria Sylvia, op. cit., p. 153.

32 Veja por exemplo a Resolução ANEEL n" 129, de 29 de abril de 1998, que autoriza a CIEN - Companhia de Interconexão Energética a importar e comercializar 1.000 MW de potência firme e respectiva energia elétrica associada proveniente do "Mercado Eléctrico Mayorista-MEM" da República Argentina. art. 5". Outros exemplos podem ser encontrados nas Resoluçōes da ANEEL 331/2000,553/2000 e $4333 / 2001$, que autorizam o estabelecimento de usinas termelétricas como produtores independentes de energia.
} 
empreendimentos demandam investimentos muito menores que as térmicas. $\mathrm{Ou}$ seja, o volume de capital investido nāo foi utilizado como um dos critérios para limitar a precariedade da autorização, ao contrário do que seria de se esperar pelos comentários tecidos anteriormente.

A doutrina, como visto, e a jurisprudência são pacíficas quanto ao caráter precário da autorizaçāo, com possibilidade de revogação sem indenizaçāo a qualquer tempo (o que não é regra no setor elétrico). Como se vê pela jurisprudência abaixo:

"ROMS. ATO ADMINISTRATIVO. TRANSPORTE PÚBLICO. AUTORIZAÇÃO. NATUREZA PRECÁRIA E DISCRICIONÁRIA. AUSÊNCIA DE DIREITO LÍQÜIDO E CERTO.

I - A autorização é ato unilateral da Administração Pública, de natureza discricionária e precária.

(STJ, RMS 5.159/RJ, Rel. Ministra LAURITA VAZ, SEGUNDA TURMA, julgado em 4.9.2001, DJ 15.10.2001, p. 252).

Voto condutor:

Caracteriza-se, este contrato administrativo, por delegação unilateral e precária da execução de serviços públicos. Sua prestação não garante ao executor estabilidade contratual, estando cingida à Administração Pública enquanto lhe bem servir. Cabe ao Poder Público decidir discricionariamente sobre a conveniência ou não da revogação do ato autorizado."

Também em decorrência da precariedade, não se prevê indenização:

"EMENTA: ADMINISTRATIVO. TRANSPORTE HIDROVIÁRIO. AUTORIZAÇÃO. PRECARIEDADE. EXTINÇÃO. INDENIZAÇÃO. LUCROS CESSANTES. DANOS EMERGENTES. NÃO CABIMENTO.

Tratando-se de delegação de prestação de serviço público por autorização, incabível a indenização postulada, tendo em vista se tratar de ato administrativo precário e discricionário" (TRF4, AC, processo 1999.71.03.001245-4, Terceira Turma, relator Eduardo Tonetto Picarelli, publicado em 20.3.2002).

[...]

TRF2, MS nº 200102010146027, Rel. Paulo Barata, 3ª T., DJ 5.11.2003. "Não há que se falar em direito subjetivo à obtenção da autorização, pois está sujeita aos critérios de conveniência e oportunidade da Administração."

O estabelecimento de prazo nas autorizações na indústria de energia elétrica concedidas pela ANEEL mostra que foi necessário adaptar um instituto que tem como base a precariedade do ato a um setor onde é preciso garantir ao investidor tempo para a amortização do capital empregado. 
Neste sentido, Sara Jane Leite ${ }^{33}$ destaca a necessidade de se reduzir a precariedade do ato autorizativo para determinadas atividades:

"Quando uma atividade implica no direito de uma coletividade em receber do Poder Público determinado serviço, a autorização de serviço público não pode ser discricionária, tem que ter caráter de estabilidade. [...] Ocorre quando a noção de serviço público não tem o condão de afastar a liberdade de iniciativa, como é o caso dos serviços prestados sem o compromisso de generalidade, modicidade de custos e continuidade".

Deve-se, no entanto, uma vez mais ressaltar as diferenças entre a legislação para os setores de energia e telecomunicações, pois para o primeiro algumas limitações à autonomia empresarial ainda são impostas em função da sua essencialidade. Isto porque pelas próprias características do setor elétrico, que se organiza na forma de uma cadeia energética, sua reestruturação, e conseqüente desverticalização das atividades, não isolou atividades de forma tão cristalina quanto ocorreu para as telecomunicaçōes.

Por exemplo, o objetivo principal da atividade do produtor independente é o de comercializar a energia produzida nas formas estabelecidas no arts. 11 da Lei $n^{\circ}$ 9.074/95 e 23 do Decreto $n^{\circ}$ 2.003/96, enquanto o autoprodutor produz energia para seu próprio consumo. ${ }^{34}$ Ambas as atividades são consideradas atividades privadas, o que as deveria submeter a um regime de direito privado. Esta é uma conclusão aceita pacificamente para o autoprodutor, mas no caso da produção independente não se pode afirmar que exista um consenso quanto ao regime a que estaria submetida esta atividade, especialmente no caso de comercialização com concessionários de serviço público, modalidade prevista no inciso I do citado art. 23.

A especificidade desta venda, cuja destinação final é uma coletividade, em relação às demais previstas no mesmo artigo, que tratam de venda de energia para grupos específicos de consumidores, é que levanta o questionamento quanto à aplicação de regras de direito privado. Nesta linha, Marçal Justen Filho: ${ }^{35}$

"Quando se estabelece que a produção independente sujeita-se a regras próprias, não se produz a desvinculação do 'produtor independente' do regime próprio de direito público e dos princípios inerentes à concessão

\footnotetext{
33 Op. cit., p. 38 .

34 Mas ressalte-se que ainda que produzindo para consumo próprio, o autoprodutor cria sobra de energia para o mercado. Nos últimos dez anos os maiores autoprodutores participaram na implantação de 25 usinas hidrelétricas e termelétricas que totalizam quase $6.000 \mathrm{MW}$, liberando energia velha, mais barata, aos consumidores cativos. AMARAL, Cristiano Abijao de. O setor elétrico despreza investimentos privados? Empresas autoprodutoras dispōem de $\mathrm{R} \$ 3$ bilhões por ano para investir em geração? Disponivel em: <http://www.canalenergia.com.br>. Acesso em: 27 abr. 2006.

35 Apud VILLELA SOUTO, Marcos Juruena. Regulaçāo da parceria para a produçāo independente de energia emergencial. In: Direito administrativo das parcerias. Rio de Janeiro: Lumen Juris, 2005, p. 295 ss.
} 
[...]. Há espaço muito mais amplo para a autonomia de vontade dos envolvidos, em face da peculiaridade da situação. Quando se enfoca a relação entre concessionário de serviço público e consumidor doméstico, está-se diante de situação econômica e jurídica totalmente desequilibrada [...]. Daí a necessidade de o poder concedente interferir e assegurar a tutela aos interesses individuais [...]. A situação se altera, porém, quando se enfocam grandes consumidores individuais e produtores individuais de energia."

Nestes casos, a intervenção do regulador é legítima, mas limitada, como esclarece Marcos Juruena Vilela Souto: ${ }^{36}$

"A inafastável ligação entre as etapas da cadeia produtiva impõe algum nível de disciplina dos contratos de venda desse insumo pelas autorizatárias, por ser indispensável à prestação do serviço de distribuição."

O nível de disciplina sugerido acima e aquele já previsto pelo art. 24 do Decreto $\mathrm{n}^{2} 2.003 / 96$, que submete os contratos de comercialização de energia à homologação do órgão regulador e fiscalizador do Poder Concedente:

"O objetivo da homologação limita-se a compatibilizar o contrato de comercialização de energia pelo produtor independente com o ato que lhe atribuiu tal direito e fixou-lhe as condiçōes de atuação. Mais não pode haver, por representar invasão indevida nos negócios empresariais, com vulneração dos princípios constitucionais da livre iniciativa e da autonomia da vontade." ${ }^{3}$

Neste sentido, o que se tem é um contrato privado cujo objeto deve ser regulado tanto no que se refere aos preços, que estão restritos a um teto legal ${ }^{38}$ definido pelo próprio regulador, quanto na adequação do serviço prestado. No entanto, a regulação não modificaria o regime jurídico desses contratos, que continuam sendo de direito privado.

De todo modo, não se pode deixar de reconhecer que há uma limitação administrativa que se impōe sobre a liberdade de contratar típica dos contratos privados, especialmente no que se refere aos preços em função do princípio da modi-

\footnotetext{
VILLELA SOUTO, Marcos Juruena, op. cit., p. 301.

VILLELA SOUTO, Marcos Juruena, op. cit., p. 301.

38 Artigo $1^{\prime \prime}, \$ 8^{\circ}$, e $2^{\circ}$, V e $\$ 4^{\prime \prime}$, da Lei n" 10.848/04. O Decreto $n^{\prime \prime} 5.163 / 2004$ prevê o "Valor Anual de Referência" em seu art. 34: "Para regular o repasse às tarifas dos consumidores finais dos custos de aquisição de energia elétrica previstos neste Decreto, a ANEEL deverá calcular um Valor Anual de Referência - VR." O artigo $7^{\circ}$ da Resolução $n^{\prime 2}$ 162/2005, por sua vez, estabelece que "o valor de repasse dos custos de aquisição de energia elétrica, às tarifas dos consumidores finais, fica limitado ao Valor Anual de Referência - VR vigente no ano de início da entrega da energia contratada". A resolução normativa ANEEL $n^{\circ}$ 167/2005 também trata desse assunto, estabelecendo, no parágrafo $3^{\circ}$ do seu artigo $3^{\circ}$ que: "A ANEEL autorizará o repasse, às tarifas dos consumidores finais, do preço da energia elétrica adquirida conforme o caput, até o limite do Valor Anual de Referência - VR vigente no ano de início da entrega da energia contratada e, nos reajustes subseqüentes, no valor atualizado pelo IPCA."
} 
cidade tarifária. Nas palavras de Alexandre Aragão (quando trata de contratos de compartilhamento de infra-estrutura):

"Nossa opinião é, portanto, que o compartilhamento tem natureza de contrato privado, mas não, evidentemente, de um contrato privado oitocentista, calcado na liberdade da vontade e no caráter essencialmente privatístico." 39

A mesma limitação se aplicaria aqui, pois se há uma livre negociação entre as partes na definição das obrigaçōes contratuais, como, por exemplo, quantidade a ser suprida, por outro lado, estes contratos de compra e venda de energia devem ser homologados pela ANEEL e há, no caso específico, uma limitação legal ao preço.

Avançando na questão da limitação da liberdade contratual entre o produtor independente e seus clientes, Maria João P. Rolim defende um regime jurídico híbrido para as autorizaçōes, pois a atividade privada da comercialização não retira a natureza de serviço público a que esta se submete ao se integrar à cadeia energética:

"Entretanto, há casos que, mesmo quando destinado a consumo privado, há um objetivo indireto de atender à coletividade, propiciando melhor aproveitamento dos potenciais de energia elétrica, e, dessa forma, haveria uma proximidade com a natureza pública do serviço [...]. Estas conclusões, contudo, não afastam a possibilidade de serem aplicáveis à atividade aspectos próprios de regime de direito privado ou mecanismos de mercado. Ao contrário, confirma a existência de um regime próprio híbrido, aplicável aos serviços públicos" 40 (grifo nosso).

Resumindo, pode-se dizer que para o produtor independente há a possibilidade de exploração de serviço de energia através de autorização dada a previsão legislativa que aplicou o conceito de mercadoria à energia elétrica nos casos de comercialização, onde não haveria prestação de serviço a uma coletividade. Seriam transações de compra e venda de energia entre grandes consumidores e PIE, situação onde não se apresentaria a necessidade de tutela por parte do órgão regulador. Marçal Justen Filho elabora a questão da seguinte forma:

"Seria ou não possível que o produtor de energia elétrica voltando ao caso da energia elétrica pretendesse 'comercializar' a energia por ele próprio produzida? A resposta afigura-se como positiva, na medida em que se mantenha a tese de que essa atividade será configurada como atividade

\footnotetext{
39 ARAGÃO, Alexandre Santos de. Compartilhamento de infra-estruturas por concessionários de serviços públicos: disciplina e natureza jurídica. In: Servidão administrativa e compartilhamento de infraestruturas: regulaçāo e concorrência. Rio de Janeiro: Forense, 2005, p. 120.

40. Op. cit., p. 157-161.
} 
econômica em sentido estrito se não estiverem presentes os pressupostos da existência de serviço público". ${ }^{41}$

Mas, como o próprio autor ressalta, "o ponto central reside em determinar os requisitos de configuração de um serviço público", o que na cadeia energética não é tarefa tão simples. Como o produtor independente tem permissão para vender energia também para concessionários de serviço público, a atividade do produtor independente atinge um serviço público, pois uma distribuidora de energia atende a necessidades de uma coletividade. $E$ aí podem estar presentes os requisitos de configuração de um serviço público, isto é, uma prestação indispensável à satisfação de necessidades essenciais à integridade do ser humano.

É evidente que o poder de intervençāo do regulador será maior quanto maior for a dependência da concessionária de serviços em relação ao contrato para cumprir com a obrigação de atendimento aos seus clientes cativos. Se determinado PIE contribuisse apenas marginalmente, não haveria grande afetação pública nesta relação comercial. Estas peculiaridades dos contratos privados sugerem que não há como estabelecer um padrão para a regulação, que acabará sendo feita caso a caso.

Já para Diogo Figueiredo e Marcos Juruena, a distinçāo do cliente não é relevante, estando o contrato privado apenas sujeito à fiscalização da ANEEL nos limites da sua competência legal, uma vez que:

"o produtor independente tem na geração de energia a sua mercadoria - arcando assim, com todos os riscos inerentes à atividade empresarial - cujo adquirente, pode ser, exemplificativamente, tanto o concessionário de serviço público ou o comercializador, como o próprio usuário final". ${ }^{42}$

No entanto, outros autores consideram que, no caso do comprador de energia ser uma concessionária de serviço público, cuja prestação de serviço afeta uma coletividade, esta circunstância afeta, na prática, o regime privado da PIE. A sua delegação formal via autorização não transformaria, então, este serviço em privado se de fato houvesse afetação pública. Veja-se uma vez mais Marçal Justen Filho a respeito:

"Insista-se em afirmar que não se admite que a Administração Pública encubra uma certa figura por meio da alteração da denominação correta. A advertência relaciona-se com a constatação de que, muitas vezes, se produz a outorga de 'autorização de serviços públicos'. Mas se impõem ao particular os encargos correspondentes a concessão ou permissão. Ou seja, a figura apresenta apenas o nome de autorização, eis que o regime jurídico apli-

\footnotetext{
4 Op. cit., p. 47.

42 MOREIRA NETO, Diogo de Figueiredo; VILLELA SOUTO, Marcos Juruena. Arbitragem em contratos firmados por empresas estatais. Revista de Direito Administrativo, v. 236, abril/junho 2004, p. 221.
} 
cável é o da permissão ou da autorização (sic). Supōe-se que a equivocada denominação, em tais casos, deriva do intento de evitar os 'inconvenientes' que essas últimas figuras produzem para a Administração - entendendo-se por inconvenientes os limites aos poderes estatais e os direitos assegurados aos particulares. (....) Por isso, não terá qualquer efeito a palavra 'autorização' quando se verificar que versa sobre o serviço público e adota regime característico de concessão ou permissão" 43 (grifo nosso).

Destaca-se no texto acima o balanceamento que o autor faz entre direitos e deveres dos diferentes tipos de outorgas. De um lado, sobre o concessionário há uma carga maior de obrigações do que para a autorizatária e, por outro lado, há um menor conjunto de garantias para esta última. Nas palavras de Dinorá Grotti: ${ }^{44}$

"O que muda substancialmente (para a autorização) é a relação da prestadora com o Poder Público, principalmente nos seguintes aspectos:

- não há contrato com o Poder Público, mas sim o estabelecimento de uma relação jurídica não-contratual, advinda de uma autorização;

- não há dever de continuidade na prestação dos serviços;

- não há deveres de universalização de serviços;

- não há direito à manutenção do 'equilíbrio econômico-financeiro';

- o direito de exploração dos serviços é por prazo indeterminado;

- os preços são livres."

Sara Jane Leite também ressalta esta diferença entre cada regime, ao observar que:

"A diferença entre serviço prestado no regime público ou no regime privado, basicamente, revela-se na perspectiva dos ônus que são imputáveis ao prestador em regime público e a falta de ônus e uma maior liberdade que se atribui ao prestador em regime privado. Basicamente, o núcleo destes ônus consiste no dever de universalização e de continuidade"45 (grifo nosso).

\subsection{As autorizaçōes são um instrumento adequado para o setor elétrico?}

A Lei Geral das Telecomunicaçōes estabelece claramente em seu art. 65 as atividades que são governadas pelo regime privado, onde não há as obrigações

\footnotetext{
43 Op. cit., p. 130.

+ Op. cit., p. 68.

45 Op. cit., p. 113.
} 
típicas de concessionária. ${ }^{46}$ Para o setor elétrico, entretanto, a inexistência de uma Lei Geral similar criou uma situação de extrema ambiguidade nos atos autorizativos. Há, por um lado, características típicas da concessão, como a exigência de continuidade na prestação do serviço e o controle de tarifas, mas, por outro lado, não há a garantia constitucional de manutenção de equilíbrio econômicofinanceiro. Há deveres que inexistiriam em regime puramente privado, como a obrigação de contribuir com um percentual de sua receita para pesquisa e desenvolvimento do setor elétrico. ${ }^{47}$ Essa situação ambígua sugere que a determinaçāo de obrigações e garantias resultou de decisões isoladas e não de um quadro conceitual bem definido.

A mesma ambigüidade também está presente quando se analisa a admissibilidade da intervenção do Poder Público em autorizatárias do setor. O contrato de compra e venda de energia é um contrato privado, mas nem por isso é pacífica a conclusão de que não possa haver ingerência do Poder Público nas suas condições, talvez até mesmo após sua homologação. Esta intervenção tem sido justificada em decorrência de princípios como modicidade tarifária, dignidade da pessoa humana e supremacia do interesse público, todos ligados ao fato de ser a energia elétrica um serviço essencial.

Tome-se, por exemplo, a decisão da $3^{\underline{a}}$ Vara da Seção Judiciária de Pernambuco em Ação Civil Pública proposta pelo Ministério Público Estadual contra a ANEEL buscando suspender os efeitos de Resolução Homologatória no 112/2005 e do Despacho $\mathrm{n}^{0} 892$, de $8 / 11 / 2004$, que autorizava a revisão tarifária prevista no contrato de concessão da CELPE - Companhia de Eletricidade de Pernambuco:

"Determino, ainda, que a ANEEL proceda a revisão do índice questionado e estabeleça o novo índice de revisão tarifária com a subtração, no seu cálculo, do custo decorrente da aquisição de energia da TERMOPERNAMBUCO, adotando como paradigma o custo da energia hidrelétrica disponível no mercado, considerando o valor de $\mathrm{R} \$ 57,51 / \mathrm{MWh}$, conforme leilão de 2005. O novo percentual definido pela ANEEL deverá incidir nos três anos seguintes [...]" (processo no $^{\circ}$ 2005.83.00.008345-6).

Ou seja, esta decisão impede o repasse à tarifa do preço contratual com base na alegação de haver energia disponível mais barata. ${ }^{48}$ Assim, o Judiciário estaria

\footnotetext{
46 FARIAS, Sara Jane Leite de, op. cit., p. 112: "A lei prevê que a nova prestadora que assume o serviço de telecomunicaçōes nāo possuirá o ônus de universalizar o serviço [...] ficando livre para atacar o mercado de seu concorrente (que adquiriu as empresas do sistema Telebrás) não consegue atender."

t: Ver o art. $2^{\circ}$ da Lei $n^{\circ} 9.991$, de 24 de julho de 2000, o qual dispōe: "As concessionárias de geração e empresas autorizadas à produção independente de energia elétrica ficam obrigadas a aplicar, anualmente, o montante de, no mínimo, $1 \%$ (um por cento) de sua receita operacional líquida em pesquisa e desenvolvimento do setor elétrico, excluindo-se, por isençāo, as empresas que gerem energia exclusivamente a partir de instalaçōes eólica, solar, biomassa, pequenas centrais hidrelétricas e cogeração qualificada."

48 A decisão compara preços de energia hídrica com preços de energia térmica, e mais, de energia originada de usina já depreciada com não depreciada, o que não está tecnicamente correto.
} 
interferindo nos termos de contrato de comercialização previamente homologado pela ANEEL, em cumprimento estrito de toda a legislaçāo pertinente às autorizações e dentro do arcabouço regulatório do Programa Prioritário de Termeletricidade (PPT) criado pelo Decreto $n^{\circ} 3.371 / 2000,{ }^{49}$ no qual Termopernambuco se insere.

Mas a jurisprudência não é pacífica neste ponto. Em outro caso, a ANEEL condicionou a homologação de um contrato de compra e venda de energia entre uma comercializadora, ENERTRADE, e uma distribuidora de energia, CERJ, à alteração do preço negociado entre as partes, pelo fato deste estar acima daquele permitido pela legislação setorial. A empresa comercializadora impetrou mandado de segurança ${ }^{50}$ contra a decisão do órgāo regulador alegando tratar-se de regime sujeito à livre negociação. Veja-se a decisão do Juiz Federal Substituto da $8^{2}$ Vara da Seção Judiciária do Distrito Federal, Marcio Barbosa Maia:

"Ademais, reputo que a condição imposta pela ANEEL à aprovação do antes mencionado contrato de compra e venda de energia contida no Ofício 696/2003-SFF/ANEEL - ajuste de cláusulas financeiras a um valor-teto - atenta contra o art. 10 da Lei $n^{\circ}$ 9.648/1998, vazado nestas letras, verbis: Art. 10. Passa a ser de livre negociação a compra e venda de energia elétrica entre concessionários, permissionários e autorizados, [...].

Ante o exposto, CONCEDO a liminar vindicada e, em conseqüência, suspendo os efeitos do OFÍCIO n 696/2003 - SFF/ANEEL."

A idéia de tratar a autorização sob o regime jurídico privado tinha o objetivo de utilizar um instrumento de outorga mais ágil e que desse maior liberdade empresarial ao investidor privado. No entanto, a simples classificação de regime privado não tem a capacidade de afastar a intervenção da Administração ou do Judiciário, como visto, nos casos acima. E mais, como para as autorizaçōes não há um contrato que define claramente direitos e deveres, esta intervenção muito provavelmente não obedecerá a um padrão pré-definido e será feita caso a caso, não importando o regime jurídico a que se submetem. Como bem esclarece Carlos Ari Sundfeld:

"Simplesmente nāo faz sentido, na atualidade, supor que as respostas a muitas dúvidas cruciais (exemplo: Pode-se negar serviço a consumidor inadimplente? Pode haver liberdade para o prestador determinar seu preço? Há responsabilidade do Estado em virtude dos danos gerados pela exe-

\footnotetext{
49. O PPT foi instituído no ano 2000 pelo Decreto $n^{2} 3.371$, de 24 de fevereiro, numa tentativa do governo de buscar ampliar as opções de nossa matriz energética, fortemente dependente da energia hídrica, e reduzir os riscos hidrológicos do sistema nacional. Por este caráter emergencial, o programa criou uma série de prerrogativas para as usinas que viessem a participar do PPT, destacando-se a garantia de suprimento de gás natural, de repasse do valor normativo à distribuidora e de financiamento pelo Banco Nacional de Desenvolvimento Econômico e Social - BNDES.

51) Mandado de segurança n" 2003.34.00.023785-2; impetrante Enertrade Comercializadora de Energia S.A.
} 
cução de serviços por empresa autorizada?) serão encontradas por meio da operação simplista de identificar o caráter público ou privado do serviço em causa, que teria o mágico condão de determinar a aplicabilidade de um regime jurídico geral. Dai a mudança total de enfoque. Não se cuida mais de discutir o caráter público ou privado de certo serviço, mas sim de identificar como ele é regulado pelo Estado no tocante ao aspecto tal e qual" (grifo nosso)

e ainda:

"Cada serviço estatal, hoje, é objeto de um universo jurídico com peculiaridades muito próprias, o que retirou da noção de serviço público uma das suas funções que era a de afirmar a especificidade do regime jurídico"51 (grifo nosso).

Ou seja, a discussão sobre o regime jurídico das autorizações não traz nenhuma luz sobre o grau de intervenção que pode sofrer uma empresa autorizada, pois este não dependerá de aspectos formais. A delegação de empreendimentos de grande porte como ocorreu no setor elétrico através de atos autorizativos não os torna imunes ao poder de intervenção do Estado. A análise destes atos para o setor elétrico mostra que, apesar de denominados formalmente de autorizações, eles estão revestidos de características da concessão exatamente porque a Administração reconheceu a necessidade de regular uma atividade que não consegue, por razōes técnicas, ser completamente desvinculada da cadeia energética, ao contrário do que se observou no processo de privatização da telefonia celular, por exemplo.

\section{Considerações finais}

Ainda que a autorização esteja prevista na Constituição Federal e na legislação infraconstitucional, seu uso não deveria ter ocorrido no setor elétrico de forma tão disseminada. Esta conclusão nada tem a ver com a discussão sobre sua legalidade ou sobre o regime jurídico a ela aplicado. Primeiro, porque vários empreendimentos autorizados pela ANEEL são caracterizados por investimentos elevados e longos períodos de amortização, não configurando, portanto, o elemento de precariedade, tornando o risco de revogação unilateral excessivo. Segundo, porque a afetação pública desses empreendimentos, decorrente da comercializaçāo de grande volume de vendas para concessionárias de serviço público - as distribuidoras de energia -, faz com que a intervenção do Poder Público possa ser considerada legítima. Estes dois elementos mitigam as vantagens da autorização vis-à-vis à concessão, pois se na partida há mais flexibilidade para o investidor privado, ao longo de sua operação o risco regulatório é maior, já que as autoriza-

SUNDFELD, Carlos Ari, op. cit., p. 33. 
das acabam por se sujeitar ao regime de deveres de uma concessionária sem seus direitos e garantias.

A decisão do regulador de delegar serviços tão complexos e de retorno de longo prazo através de autorização, um ato precário por definição, baseou-se na tentativa de compatibilizar a característica de mercadoria atribuída à energia com a afetação pública do serviço de energia elétrica. Seu o objetivo final era o de atrair capitais privados ao oferecer maior grau de autonomia das partes na negociação contratual e menor carga de obrigações. O resultado, no entanto, foi uma situação ambígua que aumenta, e não reduz, o risco regulatório.

O resultado foi que os investimentos ficaram sujeitos tanto à intervenção do Poder Público (pela afetação pública) quanto ao risco de revogação (pela precariedade do instituto da autorização). Tais riscos não foram compensados por direitos equivalentes. Se do ponto de vista de obrigaçōes as autorizações são tratadas como uma concessão, e elas têm de sê-lo, nada mais justo, afinal, que suas garantias sejam as mesmas atribuídas às concessionárias.

Concluímos, portanto, enfatizando que este debate no setor elétrico não pode ser resolvido nem no plano da constitucionalidade das autorizações nem no plano do aspecto formal das outorgas, mas sim sobre seus aspectos materiais. A opção inicial pela autorização em função da sua agilidade não cumpriu seu papel, deixando os investidores desprotegidos e sujeitos a um elevado risco jurídico e regulatório. Para investimentos de longo prazo, com amortizações que podem chegar até 30 anos, o arcabouço regulatório deve guardar coerência. $\mathrm{Na}$ falta de garantia de consistência intertemporal das decisōes do regulador, o investidor atribuirá uma taxa de risco mais elevada ao projeto, aumentando as tarifas requeridas e minando ou até mesmo anulando os ganhos de competição criados pela separação das atividades do setor.

\section{Referências bibliográficas}

AMARAL, Cristiano Abijao de. O setor elétrico despreza investimentos privados? Empresas autoprodutoras dispōem de R\$ 3 bilhōes por ano para investir em geração? Disponível em: <http://www.canalenergia.com.br>. Acesso em: 27 abr. 2006.

ARAGĀO, Alexandre Santos de. Compartilhamento de infra-estruturas por concessionários de serviços públicos: disciplina e natureza jurídica. In: ARAGÃO, Alexandre Santos de (Org.). Servidão administrativa e compartilhamento de infra-estruturas: regulação e concorrência. Rio de Janeiro: Forense, 2005. p. 89-130.

Atividades privadas regulamentadas: poder de polícia e regulaçāo. Revista Forense, v. 383, p. 3-24, 2006. 
CASTELAR, Armando Pinheiro; SADDI, Jairo. Direito, economia e mercados. Campus, 2006.

COMPARATO, Fabio Konder. As autorizaçōes de funcionamento de instituições financeiras. In: Direito público: estudos e pareceres. São Paulo: Saraiva, 1996. p. $240-252$.

DI PIETRO, Maria Sylvia Zanella. Parcerias na administração pública: concessão, permissão, franquia, terceirização e outras formas. 5. ed. São Paulo: Atlas, 2006.

FARIAS, Sara Jane Leite de. Regulação jurídica dos serviços autorizados. Rio de Janeiro: Lumen Juris, 2005.

GROTTI, Dinorá Adelaide Musetti. Teoria dos serviços públicos e a sua transformação. In: SUNDFELD, Carlos Ari. Direito administrativo econômico. São Paulo: Malheiros, 2000. p. 39-71.

JUSTEN FILHO, Marçal. Teoria geral das concessões de serviço público. São Paulo: Dialética, 2003.

LANDAU, Elena; SAMPAIO, Patrícia. Conseguirāo as PPP's atrair os investimentos pretendidos? Revista de Direito da Associação dos Procuradores do Rio de Janeiro, Rio de Janeiro: Lumen Juris, v. 17, p. 137-160, 2006.

. Setor elétrico: uma visão introdutória. In: LANDAU, Elena (Org.). Regulação jurídica do setor elétrico. Rio de Janeiro: Lumen Juris, 2006.

LANDAU, Elena; VELLOSO, Antonio Carlos. As tarifas de energia e respeito aos contratos. Valor Econômico, 23 out. 2006.

MELLO, Celso Antonio Bandeira de. Curso de direito administrativo. 15. ed. São Paulo: Malheiros, 2003.

MOREIRA NETO, Diogo de Figueiredo; VILLELA SOUTO, Marcos Juruena. Arbitragem em contratos firmados por empresas estatais. Revista de Direito Administrativo, v. 236, p. 215-261, abr./jun. 2004.

POSNER, Richard. Economic analysis of law. Boston: Little, Brown and Company, 1988.

ROLIM, Maria João C. Pereira. Direito econômico da energia elétrica. Rio de Janeiro: Forense, 2002.

SOUTO, Marcos Juruena Villela. Regulação da parceria para a produção independente de energia emergencial. In: Direito administrativo das parcerias. Rio de Janeiro: Lumen Juris, 2005. p. 295-313.

SUNDFELD, Carlos Ari. Serviços públicos e regulação estatal: introdução às agências reguladoras. In: SUNDFELD, Carlos Ari. Direito administrativo econômico. São Paulo: Malheiros, 2000. p. 17-38. 